\title{
Complex Vector Analysis and Suppression of Parallel Vibration of Distributed Power Grid Connected Converter
}

\author{
Rui Guo ${ }^{1}$, Cunxu Wang ${ }^{1}$, Shu Liu ${ }^{1}$, Xin Guan ${ }^{1}$, Wei Gao ${ }^{1}$, \\ Shuaijie Wang ${ }^{1}$ and Chuan Chen ${ }^{2}$ \\ ${ }^{1}$ Shenyang Institute of Engineering, Shenyang, China \\ ${ }^{2}$ Jinzhou Power Supply Branch, State Grid Liaoning Electric Power Supply Co. \\ Ltd, Jinzhou, China \\ gr089@sina.com
}

\begin{abstract}
With the continuous expansion of the scale of distributed power generation, multi grid connected converters often prone to oscillation problems when parallel operation.In this paper,we study the equivalent circuit of parallel connection of multi grid connected converters, system response characteristics of voltage source and in-depth analysis of the causes of the parallel oscillation of the converters.This paper analyzes converter's parallel complex vector model by complex vector and comes to a conclusion that power grid voltage feed-forward will produce strong coupling between converter so that cause oscillation parallel converters. In view of the above problems and the flow of the converter starting or the voltage fluctuation of the grid, we design a low feed forward method, that is to make the fundamental and the main sub components of the grid voltage forward without delay and for the relative high frequency components, the filter technology is used to attenuate, so as to achieve the maximum elimination of the feed-forward coupling between the converter, to prevent the occurrence of system oscillation. In order to verify the use of this paper, the theory of the parallel converter is applied in the field of $M W$ level wind field. The experimental results prove the correctness of the theory.
\end{abstract}

Keywords: grid connected converter, complex vector analysis, feed-forward coupling

\section{Introduction}

With the development of wind power generation unit, the single-level converter is common and the grid connected converter is based on LCL filter. At the same time, the hardware control of the switch device is received by the grid connected converter, and the parallel operation of the converter becomes the mainstream [1-2]. Because of the increase of the capacity of the wind field, the more the power generation units are incorporated into the generator set, the damping characteristics of the filter are changed with the parallel operation of multi converter [3-5]. In this paper, the system response characteristics of the equivalent circuit and voltage source of the parallel converter are studied, and the causes of the converter are analyzed in depth [6-7]. In this paper, we use the complex vector analysis converter parallel complex vector model to study the power grid voltage feed-forward will generate a strong coupling between the converter, so the parallel converter oscillation [8-10]. In view of the above problems and the power grid voltage fluctuations in the flow, we design a low feed forward method, for the power grid voltage, the fundamental and the main components of the low sub - delay feed forward, for, the relative high frequency components, the filter technology is used to attenuate, so as to achieve the maximum elimination of the feed-forward coupling between the converter, to prevent the occurrence of system oscillation. 


\section{2. n-Paralleled Equivalent Model of Grid Connected Converter}

To solve the practical problems of the wind field, for the majority of the wind turbine and converter for the same vendor products, in this paper, the parallel situation of the same converter in $\mathrm{n}$ platform is analyzed and studied. Normally single grid connected converter does not produce oscillation, reference to passive or active damping, so the LCL capacitor is equivalent to the series resistance $R_{f}$ and set up the common connection point (PCC) of grid connected converter to the transformer leakage inductance and transmission line equivalent impedance of $L_{t}$ [11-12]. Therefore, the equivalent topology of the LCL filter in parallel with the grid connected converter in $\mathrm{n}$ platform is shown in Figure.1. Among them, the output voltage of the $\mathrm{M}$ converter side is represented by $v_{\text {invz }}$, the converter side current $i_{\text {invzm }}$, the network side current $i_{g z m}$, current reference direction as shown in Figure, $v_{s z}$ is public connection point (PCC) voltage, $v_{g z}$ indicates the grid phase pressure, $z=u, v, w$.

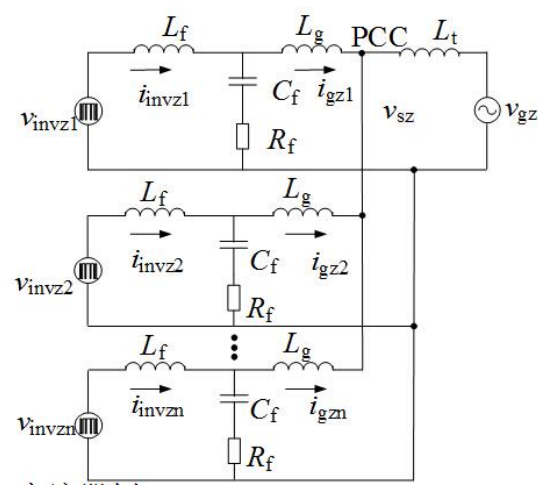

\section{Figure 1. Single Phase Equivalent Circuit of $n$-Paralleled Grid-Connected Converters}

Temporarily not consider the grid voltage, let the $\mathrm{M}$ converter output voltage $v_{\text {invzm }}$ alone, transfer function $G_{\text {invmm }}(s)=i_{\text {invzmm }}(s) / v_{\text {invzm }}(s)$, the current response of the $\mathrm{N}$ is $i_{\text {invzmm }}$, Transfer function $G_{\text {invnm }}(s)=i_{\text {invznm }}(s) / v_{\text {invzm }}(s)$. Taking the first converter as an example, according to superposition theorem, $\mathrm{N}$ converter output voltage at the same time, the response of the system is the superposition of the response of the output voltage of the converter alone $i_{\text {invz } 1}=i_{\text {invz } 11}+i_{\text {invz } 12}+\ldots+i_{\text {invzlm }}+\ldots+i_{\text {invz } I n}$. According to the symmetry of the circuit and the consistency of the system parameters, we can know the transfer function of the current response of the output voltage of the converter alone is $G_{\text {invs }}=G_{\text {inv11 }}=G_{\text {inv22 }}=\ldots=G_{\text {invnn. }}$. When the output voltage of the converter is independent of the output voltage, another converter output current response function is $G_{\text {invm }}=G_{\text {inv12 }}$ $=G_{\text {inv } 21}=\ldots=G_{\text {invmn }}=G_{\text {invnm, }}$, converter current response $i_{\text {inv }}=i_{\text {invz } 1}=i_{\text {invz } 2}=\ldots=i_{\text {invzn }}$, converter output voltage $v_{i n v}=v_{i n v z l}=v_{i n v z 2}=\ldots=v_{i n v z n}$, written in matrix.

$$
\begin{aligned}
{\left[\begin{array}{c}
i_{i n v} \\
i_{i n v} \\
\ldots \\
i_{i n v}
\end{array}\right] } & =\left[\begin{array}{c}
i_{i n v z 1} \\
i_{i n v z 2} \\
\ldots \\
i_{i n v z n}
\end{array}\right]=\left[\begin{array}{cccc}
G_{i n v 11} & G_{i n v 12} & \ldots & G_{i n v 1 n} \\
G_{i n v 21} & G_{i n v 22} & \ldots & G_{i n v 2 n} \\
\ldots & \ldots & \ldots & \ldots \\
G_{i n v n 1} & G_{i n v n 1} & \ldots & G_{i n v n n}
\end{array}\right]\left[\begin{array}{c}
v_{i n v z 1} \\
v_{i n v z 2} \\
\ldots \\
v_{i n v z n}
\end{array}\right] \\
& =\left[\begin{array}{cccc}
G_{i n v s} & G_{i n v m} & \ldots & G_{i n v m} \\
G_{i n v m} & G_{i n v s} & \ldots & G_{i n v m} \\
\ldots & \ldots & \ldots & \ldots \\
G_{i n v m} & G_{i n v m} & \ldots & G_{i n v s}
\end{array}\right]\left[\begin{array}{c}
v_{i n v} \\
v_{i n v} \\
\ldots \\
v_{i n v}
\end{array}\right]
\end{aligned}
$$


So

$\mathrm{G}_{\text {eqi }}=\frac{i_{\text {inv }}}{v_{\text {inv }}}=\mathrm{G}_{\text {invs }}+(n-1) \mathrm{G}_{\text {invm }}$

Defined as follows:

$\left\{\begin{array}{l}z_{\mathrm{f}}(s)=L_{\mathrm{f}} s \\ z_{\mathrm{g}}(s)=L_{\mathrm{g}} s \\ z_{\mathrm{t}}(s)=L_{\mathrm{t}} s \\ z_{\mathrm{c}}(s)=\frac{1}{C_{\mathrm{f}} s}+R_{\mathrm{f}}\end{array}\right.$

According to Circuit symmetry, we can get:

$\mathrm{G}_{\mathrm{eqi}}=\frac{z_{\mathrm{c}}+z_{\mathrm{g}}+n z_{\mathrm{t}}}{z_{\mathrm{f}} z_{\mathrm{c}}+\left(z_{\mathrm{f}}+z_{\mathrm{c}}\right)\left(z_{\mathrm{g}}+n z_{\mathrm{t}}\right)}$

It can be seen, compared with the single, grid inductance into $n L_{t} . G_{e q i}$ has a resonant point $\omega_{\text {resi }}$ and an anti-resonance point $\omega_{\text {anti-resi. }}$ For $\mathrm{n}$ converter, the resonant characteristics of the grid connected filter are similar to that of a single stage, and the design can also refer to a single platform. But the difference is that in accordance with the grid inductance into $n L_{t}$ design.

$\left\{\begin{array}{l}\omega_{\text {resi }}=\frac{1}{\sqrt{C_{\mathrm{f}} \frac{L_{\mathrm{f}}\left(L_{\mathrm{g}}+n L_{\mathrm{t}}\right)}{L_{\mathrm{f}}+L_{\mathrm{g}}+n L_{\mathrm{t}}}}} \\ \omega_{\text {anti-resi }}=\frac{1}{\sqrt{C_{\mathrm{f}}\left(L_{\mathrm{g}}+n L_{\mathrm{t}}\right)}}\end{array}\right.$

Similarly, the output voltage $v_{\text {invzm }}$ of the M converter is a separate function, at the point of the PCC, the voltage is $v_{s z m}$, transfer function $G_{\text {invvm }}(s)=v_{s z m}(s) / v_{\text {invzm }}(s)$. N converter output voltage at the same time, response of the system is the superposition of the response of the output voltage of the converter $v_{s z}=v_{s z l}+v_{s z 2}+\ldots+v_{s z m}+\ldots+v_{s z n}$. According to the symmetry of the circuit and the consistency of the system parameter,we can get $G_{i n v v}=G_{i n v v 1}=G_{i n v v 2}=\ldots=G_{i n v v n}$. So $G_{\text {eqvs }}(s)=v_{s z}(s) / v_{\text {inv }}(s)$.

$\left[\begin{array}{c}v_{\mathrm{sz} 1} \\ v_{\mathrm{sz} 2} \\ \ldots \\ v_{\mathrm{szn}}\end{array}\right]=\left[\begin{array}{llll}\mathrm{G}_{\text {invv1 }} & \mathrm{G}_{\text {invv2 }} & \ldots & \mathrm{G}_{\text {invvn }}\end{array}\right]\left[\begin{array}{c}v_{\text {invz1 }} \\ v_{\text {invz2 }} \\ \ldots \\ v_{\text {invzn }}\end{array}\right]$

$\mathrm{G}_{\mathrm{eqvs}}=\frac{v_{\mathrm{sz}}}{v_{\mathrm{inv}}}=n \mathrm{G}_{\mathrm{invv}}$

\section{Analysis of Converter Parallel Vibration and Complex Vector Model}

In this paper, the control of the grid connected converter is analyzed and the control system is coupled to the oscillation of the system. Complex vector analysis of three phase grid connected converter, in order to prevent grid start, power grid voltage fluctuations or 
fall caused by the current overshoot, power grid voltage feed-forward control is often needed. However, due to the presence of the transformer,the sampling points are feed forward filter in grid side inductance and leakage inductance of the transformer, that's PCC point voltage. But all converter control output will affect the PCC point voltage (near the resonance point, the influence is the largest, which is determined by the damping of the system), the converter directly sample the voltage and influence the output of the converter directly through the grid voltage feed forward. Because the value is directly controlled by the converter regulator, therefore, the presence of the grid voltage feed-forward will make a strong coupling between the converter in control (especially near the resonance point), which may cause the system oscillation [13-15]. Because of the parallel connection principle of the $\mathrm{N}$ converter and the two converters in parallel, In order to simplify the analysis, this paper will take the two converter as an example.

Two converters are used in synchronous PI regulator, and the same PI parameters.Introduced decoupling quantity, $j \omega_{g} L_{\text {total }}$, inside $L_{\text {total }}=L_{f}+L_{g}$. As the regulator and control object are described in different coordinates, the system model is established [16-19]. In this paper, we use the complex vector method to analyze. Using $d q$ coordinate system, replace s of $G_{i n v v}, G_{v g}, G_{i n v s}, G_{i n v m}$, Gig with $s+j \omega_{g}$, You can get the corresponding control object transfer function on the $d q$ coordinate system. In order to remove the influence of the high frequency harmonics of the switching frequency, the low pass filter $G_{f i}(s)$ is introduced. In addition, the $G_{f i}(s)$ is introduced to facilitate the problem of grid voltage feed-forward coupling,the system control block diagram is shown in Figure.2.

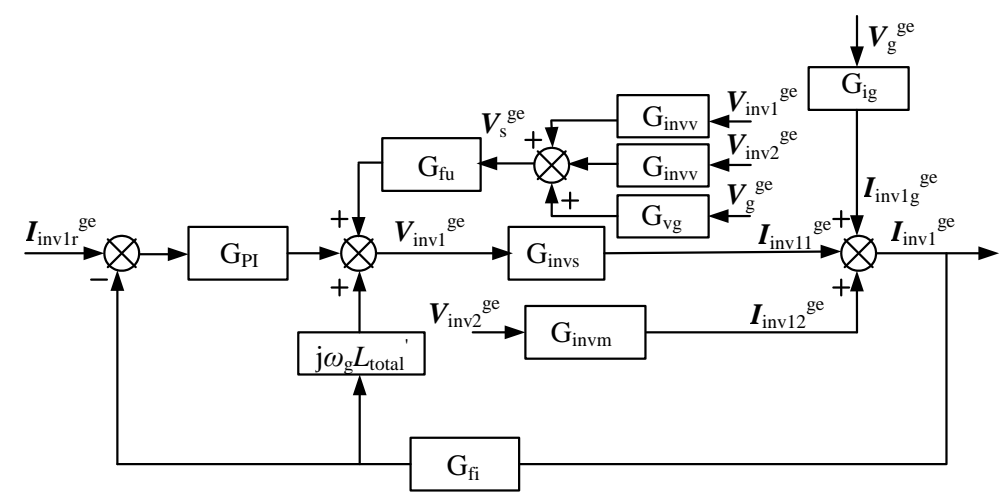

Figure 2. Control Diagram in Frame dq

$\mathrm{G}_{\mathrm{fi}}(s)=\frac{1}{T_{\mathrm{i}} s+1}$

$V_{i n v 2^{g e}}, V_{g}^{g e}$ as a perturbation, namely $V_{i n v 2^{g e}}, V_{g}^{g e}=0$ system transfer function is:

$\mathrm{G}_{\text {inv1 }}=\frac{\boldsymbol{I}_{\text {inv1 }}^{\mathrm{ge}}}{\boldsymbol{I}_{\text {invlr }}{ }_{\mathrm{ge}}}=\frac{\mathrm{G}_{\mathrm{PI}} \mathrm{G}_{\text {invs }}}{1-\mathrm{G}_{\text {invv }} \mathrm{G}_{\mathrm{fu}}+\mathrm{G}_{\mathrm{PI}} \mathrm{G}_{\text {invs }} \mathrm{G}_{\mathrm{fi}}-\mathrm{j} \omega_{\mathrm{g}} L_{\text {total }} \mathrm{G}_{\text {invs }} \mathrm{G}_{\mathrm{fi}}}$

The transfer function of $V_{g}^{g e}$ is:

$\mathrm{G}_{\text {invg }}=\frac{\boldsymbol{I}_{\text {inv1 }}^{\mathrm{ge}}}{\boldsymbol{V}_{\mathrm{g}}^{\mathrm{ge}}}=\frac{\mathrm{G}_{\mathrm{ig}}\left(1-\mathrm{G}_{\text {invv }} \mathrm{G}_{\mathrm{fu}}\right)+\mathrm{G}_{\mathrm{vg}} \mathrm{G}_{\mathrm{fu}} \mathrm{G}_{\text {invs }}}{1-\mathrm{G}_{\text {invv }} \mathrm{G}_{\mathrm{fu}}+\mathrm{G}_{\mathrm{PI}} \mathrm{G}_{\text {invs }} \mathrm{G}_{\mathrm{fi}}-\mathrm{j} \omega_{\mathrm{g}} L_{\text {total }} \mathrm{G}_{\text {invs }} \mathrm{G}_{\mathrm{fi}}}$

The transfer function of $V_{\text {inv2 }}{ }^{\text {ge }}$ is: 
$\mathrm{G}_{\text {inv2 }}=\frac{\boldsymbol{I}_{\text {inv1 }}^{\mathrm{ge}}}{\boldsymbol{V}_{\text {inv2 }}{ }_{\text {ge }}}=\frac{\mathrm{G}_{\text {invm }}\left(1-\mathrm{G}_{\text {invv }} \mathrm{G}_{\mathrm{fu}}\right)+\mathrm{G}_{\text {invv }} \mathrm{G}_{\text {fu }} \mathrm{G}_{\text {invs }}}{1-\mathrm{G}_{\text {invv }} \mathrm{G}_{\mathrm{fu}}+\mathrm{G}_{\mathrm{PI}} \mathrm{G}_{\text {invs }} \mathrm{G}_{\mathrm{fi}}-\mathrm{j} \omega_{\mathrm{g}} L_{\text {total }} \mathrm{G}_{\text {invs }} \mathrm{G}_{\mathrm{fi}}}$

The transfer function of $V_{i n v 1^{g e}}$ generated by $V_{i n v 2^{g e}}$ is:

$\mathrm{G}_{\mathrm{mv}}=\frac{\boldsymbol{V}_{\text {inv }}{ }_{\mathrm{ge}}^{\mathrm{ge}}}{\boldsymbol{V}_{\text {inv2 }}}=\frac{\mathrm{j} \omega_{\mathrm{g}} L_{\text {total }} \mathrm{G}_{\text {invm }} \mathrm{G}_{\mathrm{fi}}-\mathrm{G}_{\text {invm }} \mathrm{G}_{\mathrm{PI}} \mathrm{G}_{\mathrm{fi}}+\mathrm{G}_{\text {invv }} \mathrm{G}_{\mathrm{fu}}}{1-\mathrm{G}_{\text {invv }} \mathrm{G}_{\mathrm{fu}}+\mathrm{G}_{\mathrm{PI}} \mathrm{G}_{\text {invs }} \mathrm{G}_{\mathrm{fi}}-\mathrm{j} \omega_{\mathrm{g}} L_{\text {total }} \mathrm{G}_{\text {inv }} \mathrm{G}_{\mathrm{fi}}}$

The side current generated by the converter is the superposition of the above three.

$\boldsymbol{I}_{\text {inv1 }}{ }^{\mathrm{ge}}=\mathrm{G}_{\text {inv1 }} \boldsymbol{I}_{\text {invlr }}{ }^{\mathrm{ge}}+\mathrm{G}_{\mathrm{inv2}} \boldsymbol{V}_{\text {inv2 }}{ }^{\mathrm{ge}}+\mathrm{G}_{\text {invg }} \boldsymbol{V}_{\mathrm{g}}^{\mathrm{ge}}$

\section{Complex Vector Analysis of Parallel Oscillation Suppression}

The change of $V_{\mathrm{g}}^{\mathrm{ge}}$ interference caused by power grid voltage is similar to that of a single stage, and the transfer function is not big. If the damping design to consider the impact of the changes in the resonance point, the general form of a single, multiple parallel will not therefore oscillation.

The coupling of the converter is mainly reflected in the: As the grid voltage feed-forward exists, the output voltage of the converter II as the $V_{i n v 2^{g e}}$ of the PCC will affect the point voltage, which is determined by the control object $G_{i n v v}$. However,the converter I directly sample the $V_{\text {inv1 }}{ }^{\text {ge }}$, and through the power grid voltage feed-forward $V_{\text {inv1 }}{ }^{\text {ge }}$. The $V_{\text {inv1 }}{ }^{g e}$ in turn will affect the size of the $V_{\text {inv2 }}{ }^{\text {ge }}$, and whether the oscillation will be generated by the $G_{m v}$ transfer function is greater than that of the $0 \mathrm{~dB}$.

If no grid voltage feed-forward, that is, $G_{f u}=0$. From Figure 3, the peak value of $G_{i n v m}$ is not more than $G_{i n v s}$, regardless of the value of n. So when $\left|G_{i n v m}\right| \gg 1, G_{m v}$ is less than 0 $\mathrm{dB}$. When $G_{\text {invm }}$ is relatively small, as long as the regulator design is appropriate, the general $G_{m v}$ is still less than $0 \mathrm{~dB}$, so it will not produce oscillations, transfer function $G_{m v}$ real and imaginary part of Potter as shown in Figure.3.

$\mathrm{G}_{\mathrm{mv}}=\frac{\boldsymbol{V}_{\text {inv1 }}^{\mathrm{ge}}}{\boldsymbol{V}_{\text {inv2 }}{ }_{\mathrm{ge}}}=\frac{\left(\mathrm{j} \omega_{\mathrm{g}} L_{\text {total }}{ }^{\prime}-\mathrm{G}_{\mathrm{PI}}\right) \mathrm{G}_{\text {invm }} \mathrm{G}_{\mathrm{fi}}}{1-\left(\mathrm{j} \omega_{\mathrm{g}} L_{\text {total }}^{\prime}-\mathrm{G}_{\mathrm{PI}}\right) \mathrm{G}_{\text {invs }} \mathrm{G}_{\mathrm{fi}}}$
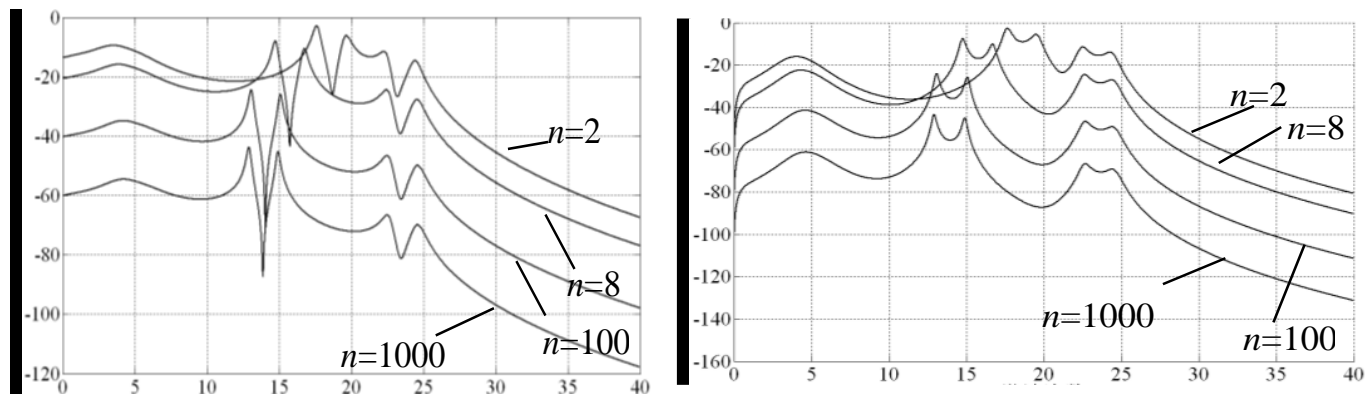

Figure 3. Bode Diagrams of $G_{m v}$ for Different Values of $\mathbf{n}$ with $G_{f u}=0$

In order to suppress the influence of voltage fluctuation on the system caused by the starting and the grid voltage, the grid voltage feed-forward is usually used. Traditional grid voltage feed-forward is to prevent over current and improve the dynamic performance, to ensure that the power grid voltage without delay, without attenuation into 
feed-forward control, equivalent to $G_{f u}=1$, but the method has the potential to cause negative effects, causing the resonance between the converter. When $G_{f u}=1$ is $G_{i n v v}$, the $G_{i n v v}$ is the same as that of $G_{i n v m}$ and $G_{i n v s}$, and the interaction between $\left|G_{i n v m}\right| \gg>1$ and $\mathrm{G}_{\mathrm{mv}}$ is more than $0 \mathrm{~dB}$. As shown in Figure.4, the oscillation frequency is near the resonance point, $n=2$, the oscillation frequency is 16 and 18 , so it is reflected that the static coordinate system is the 17 oscillation. It can be seen that the traditional grid voltage feed-forward will make the converter have a strong coupling between the converter and the system will be oscillatory. In order to suppress the oscillation, it is necessary to make the grid voltage feed-forward in the vicinity of the resonance point, such as $G_{m v}=1 /$ $(T u s+1), G_{m v}, T_{u}=0.8 m s$, and $G_{m v}$ are less than $0 \mathrm{~dB}$. But for the grid voltage feed-forward role, due to the delay of the role, will make it to the main power line interference suppression effect of poor and cause the system flow and other issues. In order to suppress the flow caused by the starting and the voltage fluctuation of the grid, the parallel oscillation of the system is not caused, and the $\left|G_{i n v v}\right|$ and $\left|G_{i n v m}\right|$ resonance peak value is not too large, but this will pay a great price.

Based on the above analysis, this paper presents a low feed forward method for the problem of the voltage feed-forward and the oscillation of the grid: to ensure that there is no time delay, the fundamental and the main low sub components of the grid voltage are guaranteed, for the grid voltage, the relative high frequency components, such as 17 or more, not to feed forward or generate sufficient attenuation by using appropriate filter technology, cutting off or weakening the I and II between the converter and the system by means of a feed-forward coupling, and the suppression of the oscillation of the system. The principle of this method is the error caused by the main disturbance of the grid voltage, and the feed forward control is all or part of the compensation, the error caused by secondary disturbance is adjusted by the feedback control. Thus, it is helpful to improve the stability and the dynamic performance of the system. The realization of the low feed forward can be realized by using the phase locked loop based on the principle of band-pass filter.
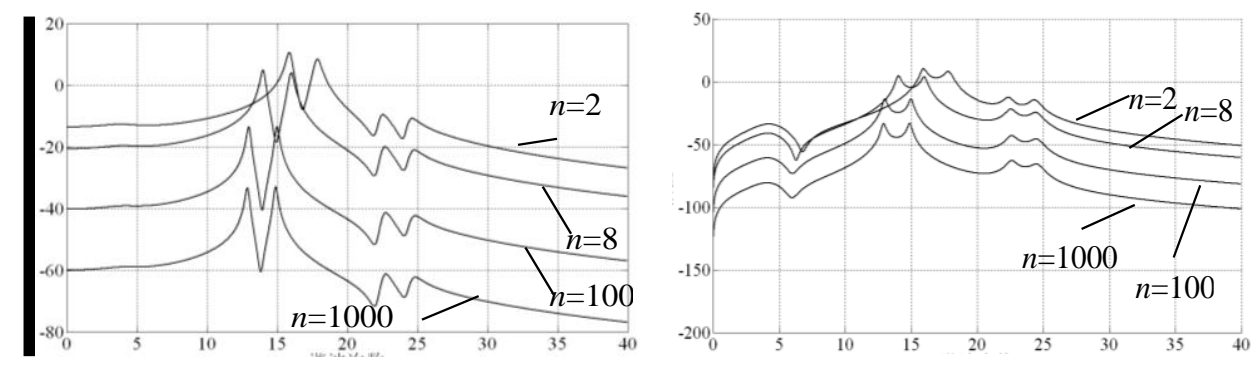

Figure 4. Bode Diagrams of $G_{m v}$ for Different Values of $n$ with $G_{f u}=1$
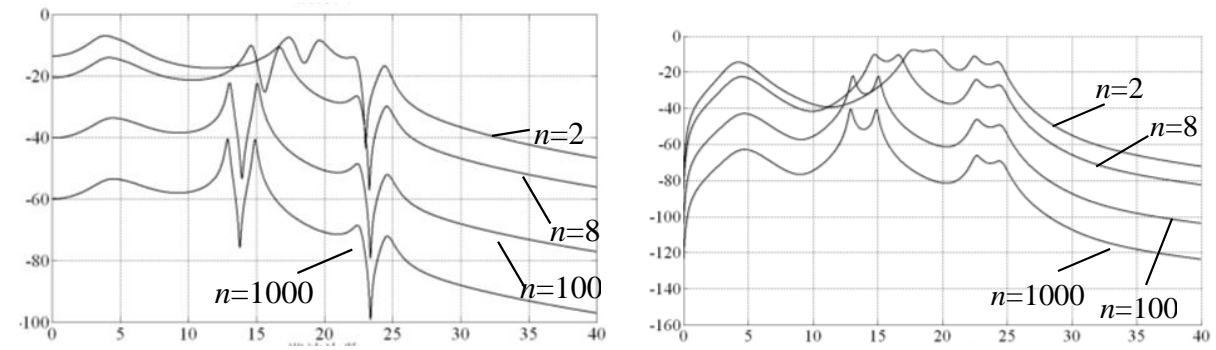

Figure 5. Bode Diagrams of $G_{m v}$ for Different Values of $n$ with $T_{u}=0.8 m s$ 


\section{Wind Farm Experiments and Conclusions}

Figure 6, shows the main wave forms of the Inner Mongolia wind field experiment. (a) $\sim$ (b) the experimental wave forms are given respectively by using the traditional grid voltage feed-forward and the low power grid voltage feed-forward. The $\mathrm{CH} 1$ is the grid line voltage $v_{\mathrm{gvw}}, \mathrm{CH} 2$ is the grid current IGU, $\mathrm{CH} 3$ is the intermediate DC bus voltage, and $\mathrm{CH} 4$ is the side current $i_{\mathrm{sB}}$ (which is positive). Figure (a) is the wind speed of $8 \mathrm{~m} / \mathrm{s}$, the use of traditional power grid voltage feed-forward control, starting a converter running well, when the second converter starts, the main variable of second converter waveform. Thus, oscillation occurs when starting the second converters, from a pulsating frequency, oscillation frequency is about 16 or 17 times. Figure (b), given the wind speed of $12 \mathrm{~m} / \mathrm{s}$, the use of low power grid voltage feed-forward, control two converters together with the experimental waveform of nearly full power, two converters from start to full power operation, no oscillation occurs. Figure (c), for the direct drive permanent magnet wind power generator is running at the rated speed of $22.5 \mathrm{r} / \mathrm{min}$, two units at the same time, one of the stator voltage $u_{s B C}$ (corresponding to $\mathrm{CH} 1$ ) and the stator current $i_{\mathrm{sB}}$ (in order to generate the direction is positive, the corresponding $\mathrm{CH} 2$ ) of the steady state.

The experimental results show that the low feed forward method, which is based on the fundamental and the main sub components of the grid voltage, has no delay. The relative high frequency components are attenuated by the corresponding filter technology. At the same time, the correctness and feasibility of the research results of the grid technology in the direct drive wind power generation system are verified.

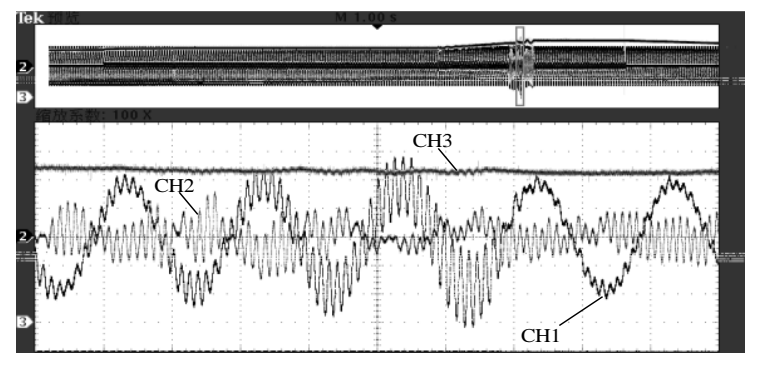

(a) experimental wave-forms using the traditional grid voltage feed-forward

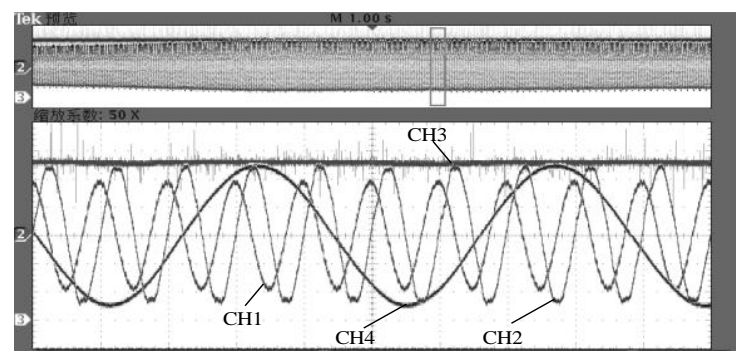

(b) the experimental wave-forms of the power grid voltage low order feed forward

\section{Acknowledgements}

This work was supported by the Natural Science Foundation of China (Grant Nos. 61372195, 61371200, 11401392, 61304069) and the Scientific Research Fund of Liaoning Provincial Education Department (Grant No. L2015378). 


\section{References}

[1] T. M. Almeida and M. S. Piedade, "High performance analog and digital PLL design", Circuits and Systems, vol. 30, no. 394, (1999).

[2] H. P. Liu, S. G. Jiang, W. Wang and D. G. Xu, "The maximum power point tracking based on the double index model of PV cells", Power Electronics and Motion Control Conference, 2009. IPEMC 09 IEEE 6th International, vol. 17, no. 2113, (2009).

[3] J. Vieira and A. M. Mota, "Maximum power point tracker applied in batteries charging with PV panels", Industrial Electronics, 2008. ISIE 2008. IEEE International Symposium on, vol. 2, no. 202, (2008) June 30-July.

[4] M. Kazmierkowski, R. Krishnan and F. Blaabjerg, "Control in Power Electronics", Selected Problems (2002).

[5] M. Ciobotaru, R. Teodorescu and F. Blaabjerg, "Control of single-stage single-phase PV inverter", Power Electronics and Applications, vol. 10, (2005).

[6] K. Ogura, T. Nishida, E. Hiraki, M. Nakaoka and S. Nagai, "Time-sharing boost chopper cascaded dual mode single-phase sine-wave inverter for solar photo-voltaic power generation system", Power Electronics Specialists Conference, 2004. PESC04. 2004 IEEE 35th Annual, vol. 6, no. 4763, (2004).

[7] X. Q. Guo, Q. L. Zhao and W. Y. Wu, "A Single-Phase Grid-Connected Inverter System With Zero Steady-State Error", Power Electronics and Motion Control Conference, 2006. IPEMC 2006. CES/IEEE 5th International, vol. 14,no. 1, (2006).

[8] D. Dong, T. Thacker, R. Burgos, D. Boroyevich and F. Wang, "On zero steady-state error of single-phase PWM inverters voltage control and phase-locked loop system", Energy Conversion Congress and Exposition, vol. 20, no. 892, (2009).

[9] R. Teodorescu, F. Blaabjerg, M. Liserre and P. C. Loh, "Proportional-resonant controllers and filters for grid-connected voltage-source converters", Electric Power Applications, vol. 153, no. 750, (2006).

[10] R. Teodorescu, F. Blaabjerg and U. Borup, "A new control structure for grid-connected LCL PV inverters with zero steady-state error and selective harmonic compensation", Applied Power Electronics Conference and Exposition, APEC 04. Nineteenth Annual IEEE, vol. 580, (2004).

[11] R. H. Middleton and G, C, Goodwin, "Improved finite word length characteristics in digital control using delta operators", IEEE Transautom. Control, vol. 31, no. 1015, (1986).

[12] F. Blaabjerg, R. Teodorescu, M. Liserre and A. V. Timbus, "Overview of Control and Grid Synchronization for Distributed Power Generation Systems” Industrial Electronics, vol. 53, no. 1398, (2006)

[13] D. Sera, R. Teodorescu, J. Hantschel and M. Knoll, "Optimized Maximum Power Point Tracker for Fast-Changing Environmental Conditions", Industrial Electronics, IEEE Transactions, vol. 55, no. 2629, (2008).

[14] N. Mutoh, M. Ohno and T. Inoue, "A Method for MPPT Control While Searching for Parameters Corresponding to Weather Conditions for PV Generation Systems", Industrial Electronics, IEEE Transactions, vol. 53, no. 1055, (2006).

[15] N. Femia, G. Petrone, G. Spagnuolo and M. Vitelli, "A Technique for Improving P\&O MPPT Performances of Double-Stage Grid-Connected Photo-voltaic Systems", Industrial Electronics, IEEE Transactions, vol. 56, no. 4473, (2009).

[16] F. Mango, M. Liserre, A. D. Aquila and A, Pigazo, "Overview of Anti-Islanding Algorithms for PV Systems. Part I Passive Methods", Power Electronics and Motion Control Conference, 2006, EPE-PEMC 2006, vol. 1878, (2006).

[17] F. Mango, M. Liserre and A. D. Aquila, "Overview of Anti-Islanding Algorithms for PV Systems. Part II: Active Methods", Power Electronics and Motion Control Conference, 2006. EPE-PEMC 2006, vol. 1884, (2006).

[18] M. Josep, J. Matas, L. G. Vicuna, M. Castilla and J. Miret, "Wireless-Control Strategy for Parallel Operation of Distributed-Generation Inverters", Industrial Electronics, IEEE Transactions, vol. 53, no. 1461, (2006).

[19] J. M. Guerrero, G. V. Luis, J. Matas, M. Castilla and J. Miret, "Output Impedance Design of Parallel-Connected UPS Inverters With Wireless Load-Sharing Control”, Industrial Electronics, IEEE Transactions, vol. 52, no. 1126, (2005). 

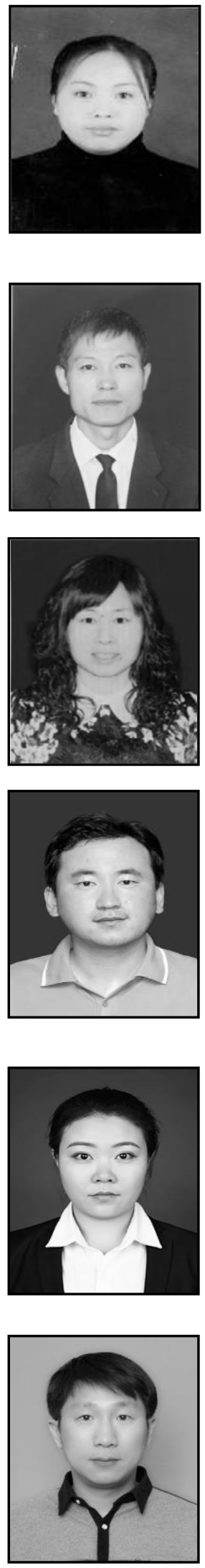

\section{Authors}

Rui Guo received the M.S degree in Power System and Automation from Shenyang University of Industry, Shenyang, China, in 2008. She is currently a associate professor with the Academy of Renewable Energy, Shenyang Institute of Engineering, Shenyang. Her current research interests include Solar Photovoltaic Generation technology and Electrical equipment.

Cunxu Wang received his M.S degree from North China Electric Power University in 1997, and now is professor and also director in school of renewable energy, Shenyang Institute of Engineering. His research interests include theoretical analysis in solar thermal system, and also complex industry process control and automation.

Shu Liu received the Ph.D. degree in Motor and Electric Appliance from Shenyang University of Technology, Shenyang, China. She is currently a lecture the School of Renewable Energy, Shenyang Institute of Engineering. Her current research is on the Wind Power generation technology.

Xin Guan received bachelor's degree in Shenyang Aerospace University in 2003. He received master's degree of Mechanical Electronic Engineering in 2009. Now he is currently working towards the doctor in school of Mechanical Engineering and Automation, Northeastern University. His current research interests include wind turbine mechanical design and mechanical reliability design and virtual 3D modeling by computer.

Wei Gao received the M.S degree in Solar Energy Engineering from Dalarna University, Borlange, Sweden, in 2009. She works in school of renewable energy, Shenyang Institute of Engineering.

Her current research interests include solar photovoltaic generation technology and analysis of power system.

Shuaijie Wang received the Master degree of PV engineering from the University of New South Wales in 2008 and proceeds $\mathrm{PhD}$ of Condensed Matter Physics in Dalian University of Technology. At present he works in school of New Energy, Shenyang Institute of Engineering. Recently, his research area includes solar photovoltaic energy, solar thermal energy, smart grid, etc. 


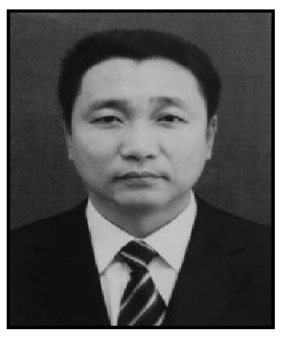

Chuan Chen received the Bachelor degree of Science from Computer \& System Science Department of Nankai University in 1991. At present he works in Jinzhou Power Supply Branch, State Grid Liaoning Electric Power Supply Co. Ltd as the vice-chief engineer and the director of human resource. Recently, his research area includes smart grid, informatization, etc. 